\title{
Reaproveitamento da Borra do Café: possibilidades de vincular a temática ao Ensino de Química
}

\author{
Rejane Danieli Leal Marquet \\ Instituto Federal do Rio Grande do Sul (IFRS) - Campus Porto Alegre \\ (rejane.marquet@poa.ifrs.edu.br)
}

Aline Grunewald Nichele
Instituto Federal do Rio Grande do Sul (IFRS) - Campus Porto Alegre

(aline.nichele@poa.ifrs.edu.br)

\begin{abstract}
Resumo: No Brasil o café foi, e continua sendo, um dos principais meios de desenvolvimento econômico, social e político. O país é o maior produtor e exportador mundial de café, e o segundo em termos de consumo, originando uma grande quantidade de resíduos, entre os quais a borra de café, proveniente do preparo da bebida café, bem como do processo de produção do café solúvel na indústria. No percurso de uma pesquisa no âmbito do Mestrado Profissional em Educação Profissional e Tecnológica (ProfEPT) do IFRS-POA, que busca implementar atividades práticas integradoras de Química pretende-se ter como cerne a temática café. Nesse trabalho apresenta-se um recorte dessa pesquisa, que objetivou investigar o reaproveitamento da borra do café com a finalidade de desenvolver conhecimento científico, vinculando a temática à elaboração de proposições didáticas relacionadas ao ensino de química. A pesquisa é caracterizada como qualitativa, descritiva, com abordagem metodológica pautada na análise documental; desenvolvida por meio de pesquisa bibliográfica realizada no Portal de Periódicos da CAPES. Foram selecionadas e analisadas 30 produções, das quais 26 representam pesquisas que visam reaproveitamento da borra do café, agregando valor comercial ao resíduo e diminuindo o impacto ambiental; e apenas 4 produções foram realizadas na área da pesquisa no ensino de Química. Identificamos práticas experimentais que tratam do reaproveitamento da borra do café e que apresentam potencial para serem adaptadas visando contribuir com o ensino de química de forma contextualizada e significativa.
\end{abstract}

Palavras-chave: Ensino de química; borra do café; experimentação.

\section{Reuse of coffee grounds: possibilities of link the theme to chemistry teaching}

Abstract: In Brazil coffee has been one of the main means of economic, social and political development. The country is the world's largest producer and exporter of coffee, and second in terms of consumption. Generating a large amount of residue, including coffee grounds, from the preparation of the coffee drink, as well as from the production process of soluble coffee in the industry. In the course of a research within the scope of the Professional Master in Professional and Technological Education (ProfEPT) at IFRS-POA, which aims to study and implement practical activities integrating chemistry is intended to have the focus on coffee. This paper presents a clipping that aimed to investigate the reuse of coffee grounds in order to develop scientific knowledge, linking the theme to the elaboration of didactic propositions related to chemistry teaching. The research is characterized as qualitative, descriptive, with methodological approach based on document analysis; developed through bibliographic research carried out in the periodics CAPES. Thirty papers were selected and analyzed, of which 26 discusses research on the reuse of coffee grounds adding commercial value to the residue and decreasing environmental impact. Only 4 productions were performed in the area of chemistry teaching. We identified experimental practices that deal with the reuse of coffee grounds, which have the potential to be adapted to contribute to the teaching of chemistry in a contextualized and meaningful approach.

Keywords: Chemistry teaching; coffee grounds; experimentation. 


\section{INTRODUÇÃO}

A cultura do café no Brasil iniciou no século XVIII, o desenvolvimento e expansão dos cafezais foi fundamental para elevar o Brasil a maior produtor de café desde o século XIX (ABIC, 2019; MAPA, 2019). Em 2018, foram produzidos no Brasil aproximadamente 60 milhões de sacas de café, 21 milhões foram consumidas internamente (ABIC, 2019).

O processamento do café ocorre em duas fases: A primeira consiste na lavagem para retirar as impurezas, separar e classificar os grãos gerando como resíduos a casca do café, pergaminho, polpa e mucilagem. A segunda fase é a produção do café torrado e moído e do café solúvel; nessa fase são gerados os resíduos líquidos e a borra de café. De acordo com os dados apresentados por Vegro e Carvalho (1993, p.2), estima-se que "uma tonelada de café verde gera 650 kg de borra", o que seria equivalente a "1,5 kg de borra por quilograma de café solúvel”, são necessárias "2,6 sacas de café verde para cada saca de café solúvel”.

Segundo Batista (2017) foram gerados em 2016 em torno de um milhão de toneladas de borra de café resultante da extração aquosa dos grãos torrados. A quantidade de resíduos produzido revela-se como um problema ambiental, porém a sua composição rica em compostos orgânicos, como ácidos graxos, aminoácidos, polifenóis, minerais e polissacarídeos (CAMPOS-VEGA et al., 2015), possibilita sua reutilização na produção de diferentes produtos de valor agregado possibilitando um destino ambiental adequado (BATISTA, 2017).

Assim, segundo estudos de Matos (2003), apenas 6\% do café colhido é utilizado na preparação da bebida. Os resíduos como a polpa, casca, a água de mucilagem é originada no processamento e a borra de café é obtida no preparo da bebida totalizam $94 \%$ de resíduos. A matéria orgânica, e os compostos inorgânicos presentes podem causar graves problemas ambientais (VEGRO; CARVALHO, 1993), fatos estes que justificam inúmeros estudos sobre o reaproveitamento desta biomassa.

A Química é uma ciência que estuda as transformações. O uso de atividades experimentais, contextualizadas com temas como a reutilização da borra de café, pode auxiliar os alunos na aprendizagem de química. Tornando o processo de ensino e aprendizagem relevante e motivador, estimulando a interação e compreensão de conceitos abstratos e complexos. 
O desenvolvimento desta pesquisa ratifica-se pela necessidade de buscar novas possibilidades e perspectivas para o ensino e aprendizagem de química. Constituída a partir da reutilização da borra de café, a temática justifica-se devido as questões sociais e ambientais envolvidas. Considera-se relevante o tema pois ao conscientizar os alunos da importância da reutilização desta biomassa viabiliza-se uma formação humana integral (MOURA, 2007) voltada ao contexto da Educação Profissional e Tecnológica do curso Técnico em Química do Instituto Federal de Educação, Ciência e Tecnologia do Rio Grande do Sul - Campus Porto Alegre (IFRS - POA). Assim, os alunos poderão ser estimulados a desenvolver e otimizar o modo como constroem seu conhecimento de forma interativa e envolvente, tornando a aprendizagem significativa.

\section{MATERIAIS E MÉTODOS}

A pesquisa apresenta características qualitativa, descritiva, com abordagem metodológica pautada na análise documental. A etapa inicial da pesquisa aqui apresentada consistiu numa pesquisa bibliográfica sobre as possibilidades de abordagem do reaproveitamento da borra do café como temática norteadora do ensino de química.

O delineamento da pesquisa de acordo com Gil (2002) consiste no planejamento de forma ampla, considerando desde a pesquisa exploratória inicial sobre o reaproveitamento da borra do café, a identificação e busca de referências, elaboração de esquemas, mapas conceituais e/ou mentais, seleção e testes das hipóteses e a previsão de análise e interpretação dos dados, bem como a organização dos dados chegando a conclusões e recomendações. A avaliação dos "achados" dessa pesquisa, permitiu a elaboração de um mapa conceitual inicial, que irá contribuir com a elaboração de proposições didáticas para realização de atividades práticas no ensino de química.

A pesquisa bibliográfica foi realizada por meio da investigação no Portal de Periódicos da Coordenação de Aperfeiçoamento de Pessoal de Nível Superior (CAPES) selecionando as seguintes periódicos e bases de dados: Journal of Chemical Education - ACS Publications, Química Nova, Scopus, Google Scholar, Education Resources Information Center - ERIC, Science Direct e Web of Science com as palavras-chave "borra de café" ,"reaproveitamento", "ensino”, "química”, 
"extração" "experimentação" isolados e combinados. Foram considerados artigo e anais de eventos, nacionais e internacionais, assim como revistas e periódicos relacionados à temática e ao ensino de Química. Selecionou-se 30 produções, consideradas potencialmente relevantes para contribuir com o ensino e aprendizagem de química.

\section{RESULTADOS E DISCUSSÃO}

Devido à quantidade de resíduo formado durante o processamento do café, muitas pesquisas vêm sendo desenvolvidas contemplando essa temática. Com intuito de conhecer estas pesquisas e verificar as possibilidades de adaptações destas para elaboração de proposições didáticas, vinculando teoria e prática no contexto do ensino de Química, selecionou-se 30 produções que são apresentadas na Tabela 1. Na tabela são explicitadas as atividades e/ou procedimentos experimentais realizados, o que permitiu identificar as diversas práticas e métodos utilizados para reaproveitar a borra do café; bem como os "achados" foram classificados quanto ao enfoque do seu conteúdo (área do ensino ou pesquisa em química) isto é, quanto à execução das atividades práticas como estratégia pedagógica no ensino de química, ou na pesquisa como desenvolvimento de métodos sem aplicação direta do procedimento em sala de aula ou laboratório de ensino.

Tabela 1- Produções vinculadas ao reaproveitamento da borra do café.

\begin{tabular}{|c|c|c|c|c|}
\hline & $\begin{array}{l}\text { Autores/anol } \\
\text { evento }\end{array}$ & Título & $\begin{array}{l}\text { Atividade/Procedimento } \\
\text { Experimental }\end{array}$ & $\begin{array}{l}\text { Enfoque } \\
\text { do } \\
\text { conteúdo }\end{array}$ \\
\hline 1 & $\begin{array}{ll}\text { MOITINHO, et } \\
\text { al.,2018 } \\
\text { Conepro III } \\
\text { V Simpósio } \\
\end{array}$ & $\begin{array}{l}\text { Caracterização do óleo } \\
\text { extraído da borra de café } \\
\text { industrial para aplicação } \\
\text { como Biodiesel }\end{array}$ & $\begin{array}{l}\text { Extração de óleo com } \\
\text { Soxhlet e hexano, } \\
\text { caracterização GC/MS }\end{array}$ & Pesquisa \\
\hline 2 & $\begin{array}{l}\text { SANTOS, J. N.; } \\
\text { HARAGUCHI, } \\
\text { D. M., } 2016 \\
\text { XIX Cong. Inic. } \\
\text { Cient. UMC }\end{array}$ & $\begin{array}{l}\text { Obtenção do biodiesel a } \\
\text { partir de resíduos de café }\end{array}$ & $\begin{array}{l}\text { Extração de óleo com } \\
\text { Ultrassom e hexano, } \\
\text { Reação de } \\
\text { transesterificação } \\
\text { produção de Biodiesel }\end{array}$ & Pesquisa \\
\hline 3 & $\begin{array}{l}\text { LAGO, R. C. A.; } \\
\text { ANTONIASSI, } \\
\text { R.,2000 } \\
\text { SPCB }\end{array}$ & $\begin{array}{l}\text { Composição de esteróis } \\
\text { em óleos de café por } \\
\text { cromatografia gasosa de } \\
\text { alta resolução }\end{array}$ & $\begin{array}{l}\text { Extração de óleo com } \\
\text { Soxhlet e éter de petróleo, } \\
\text { caracterização CG-AR }\end{array}$ & Pesquisa \\
\hline
\end{tabular}




\begin{tabular}{|c|c|c|c|c|}
\hline 4 & $\begin{array}{l}\text { LAGO, R. C. A., } \\
\text { ANTONIASSI, } \\
\text { R.; FREITAS, } \\
\text { S. C., } 2001 \\
\text { II SPCB }\end{array}$ & $\begin{array}{l}\text { Composição centesimal e } \\
\text { de aminoácidos de café } \\
\text { verde, torrado e de borra } \\
\text { de café solúvel }\end{array}$ & $\begin{array}{l}\text { Extração de óleo com } \\
\text { Soxhlet e éter de petróleo, } \\
\text { caracterização método } \\
\text { oficial AOAC } 1997\end{array}$ & Pesquisa \\
\hline 5 & $\begin{array}{l}\text { FREITAS, S. } \\
\text { P., MONTEIRO, } \\
\text { P. L., LAGO, R. } \\
\text { C. A., } 2000 \\
\text { SPCB }\end{array}$ & $\begin{array}{l}\text { Extração do óleo da borra } \\
\text { de café solúvel com } \\
\text { etanol Comercial }\end{array}$ & $\begin{array}{l}\text { Extração de óleo com } \\
\text { etanol, caracterização } \\
\text { método oficial pelos } \\
\text { métodos (AOCS, 1996) }\end{array}$ & Pesquisa \\
\hline 6 & $\begin{array}{l}\text { ROCHA C. C. } \\
\text { DA; REIS, C.; } \\
\text { CHAVES, A. R. } \\
\text { DE M., 2013 } \\
\text { VIII SPCB }\end{array}$ & $\begin{array}{l}\text { Caracterização qualitativa } \\
\text { de ácidos graxos como } \\
\text { componentes dos óleos } \\
\text { de grão de café verde, } \\
\text { café torrado e borra de } \\
\text { café }\end{array}$ & $\begin{array}{l}\text { Extração de óleo com } \\
\text { Soxhlet e hexano, } \\
\text { caracterização qualitativa } \\
\text { e CG-EM }\end{array}$ & Pesquisa \\
\hline 7 & $\begin{array}{l}\text { SARRAF et al., } \\
2016 \\
56^{\circ} \mathrm{CBQ}\end{array}$ & $\begin{array}{l}\text { Eliminando odores: O uso } \\
\text { da borra de café como } \\
\text { ferramenta no Ensino de } \\
\text { adsorção para alunos da } \\
\text { EEEFM Deodoro de } \\
\text { Mendonça }\end{array}$ & Adsorção & Ensino \\
\hline 8 & $\begin{array}{l}\text { SILVA, L.C.O.; } \\
\text { FRANCA, A.S.; } \\
\text { OLIVEIR, L.S., } \\
2010 \\
\text { COBEQ }\end{array}$ & $\begin{array}{l}\text { Utilização de borra de } \\
\text { café na produção de } \\
\text { Adsorventes para } \\
\text { remoção de compostos } \\
\text { fenólicos }\end{array}$ & $\begin{array}{l}\text { Adsorção remoção de } \\
\text { fenol tratada com KOH e } \\
\mathrm{HNO}_{3} \text {, concentração do } \\
\text { adsorvato determinada } \\
\text { UV/Vis e espectroscopia } \\
\text { vibracional infravermelho }\end{array}$ & Pesquisa \\
\hline 9 & $\begin{array}{l}\text { MOURA et al., } \\
2016 \\
\text { XXV CBCTA }\end{array}$ & $\begin{array}{l}\text { Extração e caracterização } \\
\text { da composição Lipídica } \\
\text { da borra de café robusta } \\
\text { e arábica }\end{array}$ & $\begin{array}{l}\text { Extração de óleo extrator } \\
\text { Foss e éter de petróleo } \\
\text { Caracterização GC-MS }\end{array}$ & Pesquisa \\
\hline 10 & $\begin{array}{l}\text { SILVA et al., } \\
2016 \\
\text { ACTA }\end{array}$ & $\begin{array}{l}\text { Utilização dos resíduos } \\
\text { da extração do óleo bruto } \\
\text { do café na produção de } \\
\text { material adsorvente }\end{array}$ & $\begin{array}{l}\text { Extração do óleo com } \\
\text { fluido supercrítico, } \\
\text { produção do carvão } \\
\text { ativado, cinética de } \\
\text { adsorção UV-VIS, } \\
\text { isoterma de adsorção UV } \\
\text { VIS }\end{array}$ & Pesquisa \\
\hline 11 & $\begin{array}{l}\text { VALENCIA, N. } \\
\text { R.; } \\
\text { FRANCO, D. } \\
\text { A. Z.,2010 } \\
\text { Cenicafé }\end{array}$ & $\begin{array}{l}\text { Los Subprodutos del café: } \\
\text { fuente de energía } \\
\text { Renovable }\end{array}$ & $\begin{array}{l}\text { Extração de óleo com } \\
\text { etanol ou metanol, } \\
\text { reação de } \\
\text { transesterificação para } \\
\text { produção do Biodiesel }\end{array}$ & Pesquisa \\
\hline 12 & $\begin{array}{l}\text { TOREZAN, R. } \\
\text { M.; SANTOS, F. } \\
\text { C. S., } 2017 \\
17 \quad \text { o CONIC- } \\
\text { SEMESP }\end{array}$ & $\begin{array}{l}\text { Reutilização da borra de } \\
\text { café para produção de } \\
\text { biocombustível }\end{array}$ & $\begin{array}{l}\text { Extração de óleo com } \\
\text { Soxhlet e hexano, reação } \\
\text { de transesterificação } \\
\text { para produção do } \\
\text { Biodiesel }\end{array}$ & Pesquisa \\
\hline
\end{tabular}




\begin{tabular}{|c|c|c|c|c|}
\hline 13 & $\begin{array}{l}\text { FIGUEIREDO, A. C. } \\
\text { F.; BOTARI, J. C., } \\
2017 \\
\text { XVII Safety, Health } \\
\text { and Environment } \\
\text { World Congress }\end{array}$ & $\begin{array}{l}\text { Remoção de Cloridrato } \\
\text { de metiltiamina por } \\
\text { adsorção utilizando } \\
\text { carvão ativado } \\
\text { produzido } \\
\text { a partir da Borra de café }\end{array}$ & $\begin{array}{l}\text { Preparo carvão ativado, } \\
\text { adsorção, caracterização } \\
\text { físico-química }\end{array}$ & Pesquisa \\
\hline 14 & $\begin{array}{l}\text { MARIANO, F.A.F.; } \\
\text { COUCEIRO, P.R.C., } \\
2015 \\
\text { Rev. Virtual Quim. }\end{array}$ & $\begin{array}{l}\text { Compósitos à base de } \\
\text { carvão ativado de borra } \\
\text { oleosa e óxidos de ferro } \\
\text { para remoção de } \\
\text { contaminantes em meio } \\
\text { Aquoso }\end{array}$ & $\begin{array}{l}\text { Produção de carvão } \\
\text { ativado Adsorção, } \\
\text { isotermas, } \\
\text { caracterização FTIR, } \\
\text { TGA-DTA, } \\
\text { MEV, DRX e UV-vis }\end{array}$ & Pesquisa \\
\hline 15 & $\begin{array}{l}\text { SOMNUK, K.; } \\
\text { EAWLEX, P.; } \\
\text { PRATEEPCHAIKUL, } \\
\text { G., } 2017 \\
\text { Agric and Natural } \\
\text { Resources }\end{array}$ & $\begin{array}{l}\text { Optimization of coffee oil } \\
\text { extraction from spent } \\
\text { coffee grounds using } \\
\text { four solvents and } \\
\text { prototype-scale } \\
\text { extraction using } \\
\text { circulation process }\end{array}$ & $\begin{array}{l}\text { Extração de óleo com } \\
\text { soxhlet e } \\
\text { hexano, etanol } \\
\text { anidro, etanol } \\
\text { hidratado ou metanol }\end{array}$ & Pesquisa \\
\hline 16 & $\begin{array}{l}\text { FARIA et al., } \\
2018 \\
\text { XXII COBEQ, XVII } \\
\text { ENBEQ }\end{array}$ & $\begin{array}{l}\text { Desenvolvimento } \\
\text { sabonete de } \\
\text { com adiçção do óleo } \\
\text { extraído da borra do } \\
\text { café }\end{array}$ & $\begin{array}{l}\text { Extração de óleo com } \\
\text { Soxhlet e etanol, reação } \\
\text { de } \\
\text { saponificação, } \\
\text { caracterização com } \\
\text { testes físico-químicos, }\end{array}$ & Pesquisa \\
\hline 17 & $\begin{array}{l}\text { ALBUQUERQUE et } \\
\text { al. } 2016 \\
\text { XXI COBEQ } \\
\text { XVI ENBEQ }\end{array}$ & $\begin{array}{l}\text { Cinética de secagem da } \\
\text { borra de café em estufa } \\
\text { com circulação de ar }\end{array}$ & $\begin{array}{l}\text { Estudo da cinética de } \\
\text { secagem da borra de } \\
\text { café }\end{array}$ & Pesquisa \\
\hline 18 & $\begin{array}{l}\text { RAMOS et al., } 2018 \\
\text { Revista Dissertar }\end{array}$ & $\begin{array}{l}\text { Produção de } \\
\text { adsorventes a base de } \\
\text { borra de café } \\
\text { industrializado e folhas } \\
\text { de Corymbia citriodora } \\
\text { (eucalipto limão) }\end{array}$ & $\begin{array}{l}\text { Produção do adsorvente, } \\
\text { carbonização, ativação, } \\
\text { caracterização físico- } \\
\text { químicas }\end{array}$ & Pesquisa \\
\hline 19 & $\begin{array}{l}\text { JENKINS et al., } \\
2014 \\
\text { ACS }\end{array}$ & $\begin{array}{l}\text { Effect of the type of } \\
\text { bean, processing, and } \\
\text { geographical location on } \\
\text { the biodiesel produced } \\
\text { from waste coffee } \\
\text { ground }\end{array}$ & $\begin{array}{l}\text { Extração de óleo, } \\
\text { Reação de } \\
\text { transesterificação para } \\
\text { produção do Biodiesel }\end{array}$ & Pesquisa \\
\hline 20 & $\begin{array}{l}\text { KHENNICHE, I.; } \\
\text { BENISSAD- } \\
\text { AISSANI, } \\
\text { F., } 2010 \\
\text { ACS }\end{array}$ & $\begin{array}{l}\text { Adsorptive Removal of } \\
\text { Phenol by Coffee } \\
\text { Residue Activated } \\
\text { Carbon and Commercial } \\
\text { Activated Carbon: } \\
\text { Equilibrium, Kinetics, } \\
\text { And Thermodynamics }\end{array}$ & $\begin{array}{l}\text { Preparo carvão } \\
\text { ativado, adsorção, } \\
\text { equilíbrio, cinética e } \\
\text { termodinâmica da } \\
\text { reação de adsorção }\end{array}$ & Pesquisa \\
\hline
\end{tabular}




\begin{tabular}{|c|c|c|c|c|}
\hline 21 & $\begin{array}{l}\text { MOUSTAFA } \\
\text { et al. } \\
2013 \\
\text { ACS }\end{array}$ & $\begin{array}{l}\text { Utilization of torrefied } \\
\text { coffee grounds as } \\
\text { reinforcing agent to } \\
\text { produce high-quality } \\
\text { biodegradable pbat } \\
\text { composites for food } \\
\text { packaging applications }\end{array}$ & Compósito biodegradável & Pesquisa \\
\hline 22 & $\begin{array}{l}\text { THIRÉ et al., } \\
2005 \\
8^{\circ} \mathrm{CBPOL}\end{array}$ & $\begin{array}{l}\text { Proveitamento de } \\
\text { resíduos da indústria } \\
\text { cafeeira para a } \\
\text { obtenção de } \\
\text { compósitos } \\
\text { termoplásticos à base } \\
\text { de amido }\end{array}$ & Bioplástico & Pesquisa \\
\hline 23 & $\begin{array}{l}\text { CABRAL, M. } \\
\text { S.; MORIS, V. } \\
\text { A. S., } 2010 \\
\text { XXX ENEGEP }\end{array}$ & $\begin{array}{l}\text { Reaproveitamento da } \\
\text { borra de café como } \\
\text { medida de } \\
\text { minimização } \\
\text { geração de resíduos }\end{array}$ & $\begin{array}{l}\text { Coleta seletiva, pré-tratamento, } \\
\text { armazenamento, extração do } \\
\text { óleo com etanol }\end{array}$ & Pesquisa \\
\hline 24 & $\begin{array}{l}\text { FONSECA et } \\
\text { al., } 2015 \\
\text { II Sem. Univ. } \\
\text { UNILAB }\end{array}$ & $\begin{array}{l}\text { O aproveitamento da } \\
\text { biomassa do café na } \\
\text { produção de } \\
\text { Biocombustíveis }\end{array}$ & $\begin{array}{l}\text { Extração do óleo, reação de } \\
\text { transesterificação para } \\
\text { produção de biodiesel, uso de } \\
\text { extrato etanólico da borra do } \\
\text { café como indicador de pH }\end{array}$ & Pesquisa \\
\hline 25 & $\begin{array}{l}\text { CHAVAN et } \\
\text { al., } \\
2016 \\
\text { ACS }\end{array}$ & $\begin{array}{l}\text { Spent coffee } \\
\text { bioelastomeric } \\
\text { composite foams for } \\
\text { the removal of } \mathrm{pb}^{2+} \text { and } \\
\mathrm{hg}^{2+} \text { from water. }\end{array}$ & $\begin{array}{l}\text { Adsorção, produção de filtro } \\
\text { para remoção de } \mathrm{Pb}^{2+} \mathrm{e} \mathrm{Hg}^{2+}\end{array}$ & Pesquisa \\
\hline 26 & $\begin{array}{l}\text { BATISTA et } \\
\text { al., } 2016 \\
\text { XXI BOBEQ } \\
\text { XVIENBEQ }\end{array}$ & $\begin{array}{l}\text { Extração do óleo da } \\
\text { borra do café: } \\
\text { Alternativa para } \\
\text { redução dos impactos } \\
\text { ambientais }\end{array}$ & $\begin{array}{l}\text { Extração com Soxhlet e hexano } \\
\text { do óleo da borra do café }\end{array}$ & Pesquisa \\
\hline 27 & $\begin{array}{l}\text { XAVIER,L. F.; } \\
\text { LISBOA, } \quad \text { T. } \\
\text { S.; LULA, I., } \\
2017 \\
\text { Science } \\
\text { Amazonia }\end{array}$ & $\begin{array}{l}\text { Reaproveitamento da } \\
\text { Borra de Café na } \\
\text { Obtenção de Biodiesel } \\
\text { e de Carvão Ativado } \\
\text { Para Tratamento de } \\
\text { Rejeitos Industriais } \\
\text { Têxteis. }\end{array}$ & $\begin{array}{l}\text { Extração do óleo, reação de } \\
\text { transesterificação,caracterização } \\
\text { RMN }{ }^{1} H \text { e GC- GAS, produção } \\
\text { de carvão ativo e testes de } \\
\text { adsorção. }\end{array}$ & Pesquisa \\
\hline 28 & $\begin{array}{l}\text { BENDALL et } \\
\text { al., } \\
2015 \\
\text { ACS }\end{array}$ & $\begin{array}{l}\text { Showcasing Chemical } \\
\text { Engineering Principles } \\
\text { through the Production } \\
\text { of Biodiesel from Spent } \\
\text { Coffee } \\
\text { Grounds }\end{array}$ & $\begin{array}{l}\text { Extração do óleo a quente e frio } \\
\text { com heptano ou etanol, reação } \\
\text { de transesterificação para } \\
\text { produção do biodiesel, índice de } \\
\text { refração. Realizado com ensino } \\
\text { médio. }\end{array}$ & Ensino \\
\hline
\end{tabular}




\begin{tabular}{|c|c|c|c|c|}
\hline 29 & $\begin{array}{l}\text { CUNHA et al., } \\
2018 \\
\text { Quim. Nova }\end{array}$ & $\begin{array}{l}\text { Experimento com } \\
\text { abacate, borra de café, } \\
\text { licuri e leite de coco } \\
\text { para extração de óleo, } \\
\text { produção de biodiesel } \\
\text { e análise espectral }\end{array}$ & $\begin{array}{l}\text { Extração do óleo com Soxhlet e } \\
\text { hexano, reação de } \\
\text { transesterificação para produção } \\
\text { do Biodiesel de coco, abacate, } \\
\text { borra de café e licuri, } \\
\text { caracterização IV, } \\
\text { Experimentos realizados no } \\
\text { ensino superior. }\end{array}$ & Ensino \\
\hline 30 & $\begin{array}{l}\text { ORECCHIO et } \\
\text { al., } \\
2001 \\
\text { JCE }\end{array}$ & $\begin{array}{l}\text { Recovery and } \\
\text { Reutilization of } \\
\text { Waste Matter from } \\
\text { Coffee } \\
\text { Preparation } \\
\text { An Experiment for } \\
\text { Environmental Sciene } \\
\text { Courses }\end{array}$ & $\begin{array}{l}\text { - Extração de óleo, reação de } \\
\text { saponificação, caracterização } \\
\text { qualitativa, físico-química e, } \\
\text { cromatografia gasosa, análise } \\
\text { elementar e espectroscopia de } \\
\text { absorção atômica, } \\
\text { Experimentos realizados no } \\
\text { ensino superior. }\end{array}$ & Ensino \\
\hline
\end{tabular}

Dentre essas 30 produções (Tabela 1) evidencia-se que 26 referem-se à pesquisa na área da pesquisa em química visando desenvolver e otimizar métodos e procedimentos, a serem reproduzidos em laboratórios, indústrias ou centros de pesquisa, com objetivo de reaproveitar a biomassa, borra de café. Pode-se observar uma grande variedade de técnicas e métodos que são utilizados na tentativa de apresentar diferentes soluções para reduzir a quantidade de substâncias provenientes da borra do café desperdiçadas como resíduo, causando prejuízos financeiros e ambientais.

Destacam-se pesquisas sobre os processos de extração do óleo da borra do café; este óleo pode ser caracterizado com uso de diferentes técnicas e equipamentos e ser utilizado em reações para a produção de sabão (reação de saponificação) e para a produção de biodiesel (reação de transesterificação). A fração sólida da borra do café pode ser reaproveitada produzindo-se carvão ativado, adsorventes, compósitos biodegradáveis, bioplástico. Representando assim, possibilidades de vincular a temática café ao ensino de química analítica, orgânica, ambiental e físico-química.

Na Figura 1 são esquematizados (e associados às respectivas referências os 26 textos relacionados à borra do café no âmbito da pesquisa em Química) os diversos processos de extração, originando a fração oleosa e as possibilidades de reações e testes de caracterização para ela; bem como para a fase sólida, a possibilidade de produção de adsorvente.

Os "achados" compilados na Figura 1 poderão servir de base para elaboração de atividades práticas a serem desenvolvidas nas disciplinas de Química no curso 
técnico em Química do IFRS-POA, visando proporcionar uma aprendizagem significativa.

Figura 1 - Esquema das atividades/procedimentos experimentais e respectivas referências.

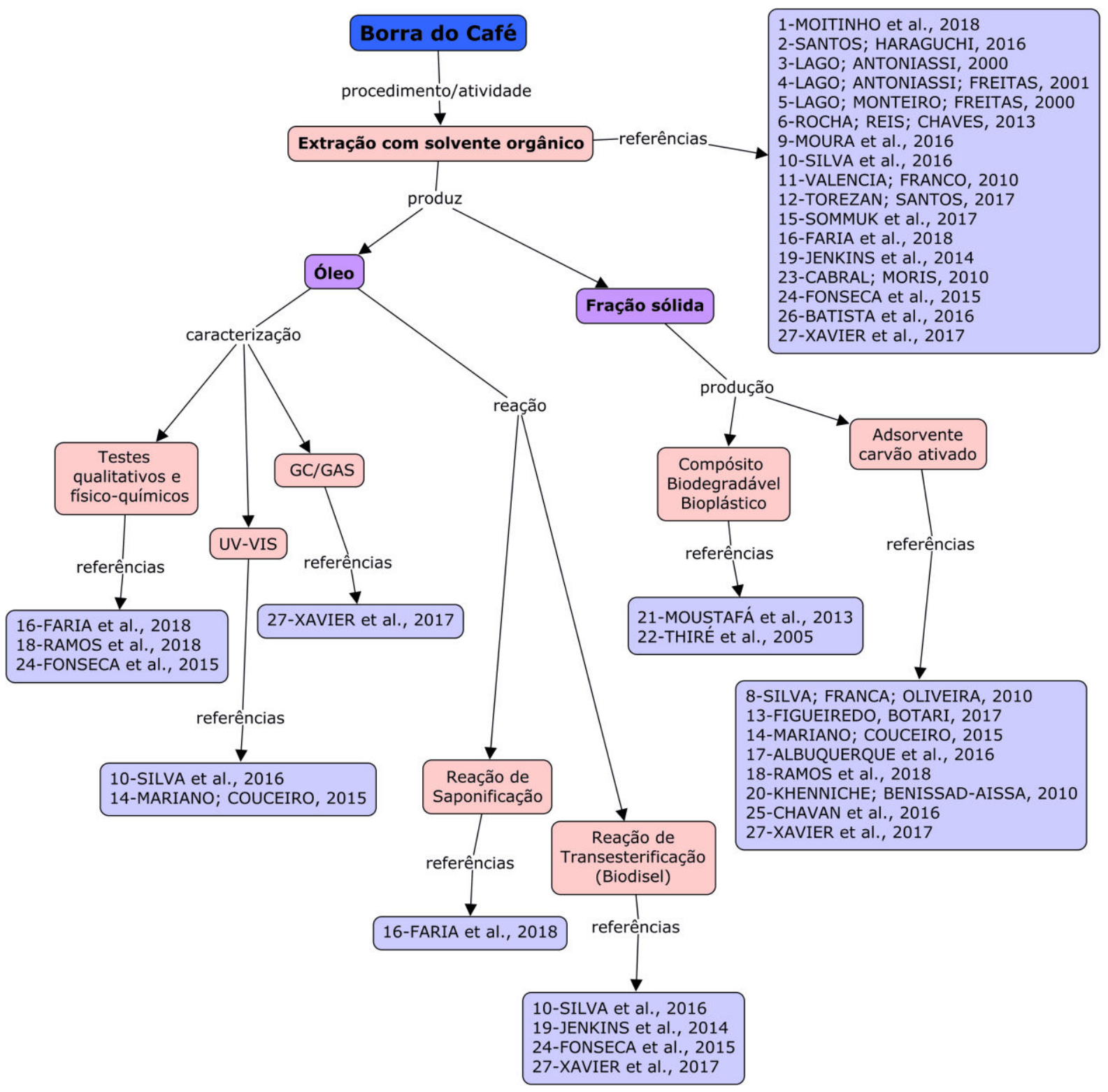

Com aplicação direta no ensino de química foram identificadas 4 produções, Sarraf et al. (2016); Bendall et al. (2015); Cunha et al. (2018) e Orecchio et al. (2001).

Sarraf et al. (2016) realizou uma atividade prática com alunos do ensino fundamental utilizando a borra de café como adsorvente para eliminar odor de peixe.

Bendall et al. (2015) realizou a produção de biodiesel com o óleo extraído da borra do café. Para a extração do óleo utilizou como solvente o heptano e o etanol, 
produzindo óleos com diferentes composições químicas. A reação de transestereficação para produção de biodiesel, foi realizada em atividade prática com alunos do ensino médio que utilizaram ambos os óleos extraídos e puderam, ao final do experimento, comparar o biodiesel produzido com esses diferentes óleos. Cunha et al. (2018) e Orecchio et al. (2001) realizaram atividades práticas com alunos do ensino superior.

Cunha et al. (2018) realizou as atividades práticas na aula de Química Orgânica Experimental. Na primeira aula realizaram a extração do óleo de abacate, coco, borra de café e licuri. Com a borra de café utilizou-se hexano como solvente. $\mathrm{Na}$ segunda aula realizaram a reação de transesterificação para obtenção do biodiesel; a análise do biodiesel foi realizada com técnica instrumental para obtenção dos espectros. No final as informações das equipes foram compartilhadas para análise comparativa dos espectros dos diferentes óleos.

Orecchio et al. (2001) realizou extração do óleo da borra do café e posterior produção de sabão com uso do mesmo. Elaborou proposições didáticas que visavam estimular os alunos a se interessar pelo conhecimento científico, demonstrando a importância da análise instrumental, da cromatografia gasosa, da espectroscopia de absorção atômica e da análise elementar. Essas técnicas de análise são importantes em cursos como química, biologia, ciências ambientais, despertam curiosidade e atenção dos alunos ao serem vinculadas a fatos cotidianos.

\section{CONSIDERAÇÕES FINAIS}

Diante dos resultados apresentados neste trabalho identificou-se possibilidades de vincular a temática café ao ensino de química analítica, orgânica, ambiental e físico-química. Uma das possibilidades identificadas foi 0 reaproveitamento dos resíduos produzidos, minimizando os prejuízos ao meio ambiente; com isso torna-se relevante a utilização da temática para a problematização de aulas experimentais a serem realizadas utilizando a borra do café como matéria-prima.

A partir desta pesquisa pretende-se viabilizar o reaproveitamento da borra do café para vincular de maneira significativa a experimentação no ensino de Química à temática café, associando a teoria e a prática. 
Nesse contexto, algumas das atividades experimentais vinculadas à temática Café (Figura 1), desenvolvidas no âmbito da pesquisa em química mas com potencial para serem adaptadas e utilizadas no ensino de química, irão compor uma Sequência Didática (SD), que será desenvolvida como produto educacional oriundo da pesquisa de mestrado em desenvolvimento no âmbito do mestrado ProfEPT. Por meio dessa SD busca-se desenvolver atividades práticas integradoras que vinculem o conhecimento e os métodos desenvolvidos na área da pesquisa em química à prática pedagógica no ensino de química, viabilizando a aprendizagem significativa no ensino profissional, em especial junto ao Curso Técnico em Química do IFRS Campus Porto Alegre.

\section{REFERÊNCIAS}

ALBUQUERQUE, Juliana; ALMEIDA, Marcelo; SOUZA, Elibe Silva; SANTIAGO, Ângela Maria; BATISTA, Gustavo Luiz Araújo Souto; ARAÚJO, Mikael Bernardo Vasconcelos de. Cinética de secagem da borra de café em estufa com circulação de ar. In:XXI Congresso Brasileiro de Engenharia Química; XVI Encontro Brasileiro sobre o Ensino de Engenharia Química. Anais. 25 a 29 de setembro de 2016. Fortaleza/CE. Disponível em: <https://proceedings.science/cobeq/cobeq-2016/papers/cinetica-de-secagem-daborra-de-cafe-em-estufa-comcirculacao-de-ar>. Acesso em: 16 Mar. 2019.

ASSOCIAÇÃO BRASILEIRA DA INDUSTRIA DE CAFÉ (ABIC). História. Disponível em: <http://abic.com.br/cafecom/historia/> Acesso em: 05 mar. 2019.

BATISTA G. L. A. S.; SOUZA, E. S.; ALMEIDA, M. M.; ALBURQUERQUER, C.J.; ARAUJO, M. B. V.; ARAÚJO, H. W. Extração do Óleo da Borra do Café: Alternativa para redução dos Impactos Ambientais. In: XXI Congresso Brasileiro de Engenharia Química - XXI COBEQ; XVI ENBEQ- XVI Encontro Brasileiro sobre o Ensino de Engenharia Química. Anais. Fortaleza - CE. 25 a 29 de set 2016. Disponível em: $<$ https://proceedings.science/cobeq/cobeq2016/papers/extracao-do-oleo-da-borrado-cafe\%3A-alternativa-para-reducao-dos-impactos-ambientais> Acesso em: 5 Jun 2019.

BATISTA, Michelle J. P. de Azevedo. Desenvolvimento e caracterização de filmes derivados da borra de café submetida a tratamento com peróxido de hidrogênio alcalino. Dissertação (mestrado) - Universidade Federal de Minas Gerais, Faculdade de Farmácia, Programa de Pós- Graduação em Ciência de Alimentos. 2017. 106 f.: il. Disponível em: <http://hdl.handle.net/1843/BUOS-BATG5G>. Acesso em: 5 Mar.2019. 
BENDALL, Sophie; BIRDSALL-WILSON, Max; JENKINS, Rhodri; CHEW, Y. M. John; CHUCK, Christopher J. Showcasing Chemical Engineering Principles through the Production of Biodiesel from Spent Coffee Grounds. Journal of Chemical Education, v. 92, n.4, p. 683-687, 2015. DOI: 10.1021/ed500824z

CABRAL, Mariana Szente; MORIS, Virginia Aparecida da Silva. Reaproveitamento da borra de café como medida de minimização da geração de resíduos. In: XXX Encontro Nacional de Engenharia de Produção. Anais. São Carlos SP, Brasil, 12 a 15 out. 2010. Disponível em:

<http://www.abepro.org.br/biblioteca/enegep2010_tn_stp_121_788_17072.pdf> Acesso em: junho 2019 CAMPOS-VEGA, Rocio; LOARCA-PIÑA, Guadalupe;

VERGARA-CASTAÑEDA, Hayd A.; OOMAH, B. Dave. Spent coffee grounds: A review on current research and future prospects. Trends in Food Science \& Technology, v. 45, n.1, p. 24 -36. 2015. doi:10.1016/j.tifs.2015.04.012

CHAVAN, Asmita A.; PINTO, J.; LIAKOS, I.; BAYER, I. S.; LAUCIELLO, S.; ATHANASSIOU, A.; FRAGOULI, D.. Spent coffee bioelastomeric composite foams for the removal of $\mathrm{Pb}^{2+}$ and $\mathrm{Hg}^{2+}$ from water. ACS Sustainable Chemistry \& Engineering, v. 4, n. 10, p. 5495-5502. 2016.

DOI:10.1021/acssuschemeng.6b01098

CUNHA, Silvio; RODRIGUES, Marina Costa; MATTOS, Rosiene Reis; TEIXEIRA, Leonardo Sena Gomes; SANTOS, Airam Oliveira; SANTOS, Elaine V. S.; SOUZA, Rauan S.; ANDRADE, Givaldo dos Santos; DE PAULA, Rodrigo; DE JESUS, Djane S.. Experimento com abacate, borra de café, licuri e leite de coco para extração de óleo, produção de biodiesel e análise espectral. Química Nova, São Paulo, v. 41, n. 6, p. 691-698, Jun 2018. Disponível em:

$<$ http://www.scielo.br/scielo.php?script=sci_arttext\&pid=S010040422018000600691\& Ing=en\&nrm=iso>. Acesso em: 25 mar 2019. http://dx.doi.org/10.21577/01004042.20170213

FARIA, A. P. C; CAROTTA, M. S. L. M; FRAGUAS, N. A. M. K; NETO, M. R. F; MENDES, M. F; PEREIRA, C. S.S..Reaproveitamento do óleo extraído da borra do café para a produção de sabonete glicerinado. In: XXII Congresso Brasileiro de Engenharia Química. Anais. São Paulo: Blucher, vol. 1 num. 5. p. 1541-1544,2018. Disponível em: <https://www.proceedings.blucher.com.br/articledetails/reaproveitamento-do-leo-extrado-daborra-do-caf-para-a-produo-de-saboneteglicerinado-28791>. Acesso em: 03 mar 2019.

FIGUEIREDO, Ana Carolina Ferreira; BOTARI, Janaina Conversani . Remoção de cloridrato de metiltiamina por adsorção utilizando carvão ativado produzido a partir da borra de café. In: XVII Safety, Health and Environment World Congress. Anais. July 09-12, 2017, Vila Real, PORTUGAL DOI 10.14684/SHEWC.17.2017.109-114

FONSECA, Aluísio Marques da; OLIVEIRA, Carla Patricia Costa; COLARES, Regilany Paulo; NASCIMENTO, Rayane Paula do. O aproveitamento da biomassa do café na produção de biocombustíveis. In: II SEMANA UNIVERSITÁRIA DA UNILAB; Anais. Ceará e Bahia.12 a 14 de nov 2015, Disponível em: 
<http://semanauniversitaria.unilab.edu.br/gerenciar/download.php?arquivo=../submis sao/trabalhos/da4f3c67f79

bab7c31954b2fec350938.pdf\&novoNome=761_O_APROVEITAMENTO_DA_BIOMA SSA_DO_CAFE_UM_ESTUDO_E_APLICACAO__DOS_OLEOS_FIXOS>. Acesso em: 05 jun 2019

FREITAS, Suely Pereira; MONTEIRO, Patrícia Lobo; LAGO, Regina Celi A. Extração do óleo da borra de café solúvel com etanol comercial. In: Simpósio de Pesquisa dos Cafés do Brasil. Anais. Poços de Caldas, MG v. 1 p. 740-743. 2000. Disponível em: <http://www.sbicafe.ufv.br/handle/123456789/882>. Acesso em: 21 fev. 2019

GIL, Antônio Carlos. Como elaborar projetos de pesquisa. 4. ed. - São Paulo: Atlas, 2002

JENKINS, Rhodri W.; STAGEMAN, NatashaE.; FORTUNE, Christopher M.; CHUCK, Christopher J.. Effect of the type of bean, processing, and geographical location on the biodiesel produced from waste coffee grounds. Energy \& Fuels, v. 28, $n$. 2, $p$. 1166-1174.2014. doi:10.1021/ef4022976

KHENNICHE, Lamia; BENISSAD-AISSANI, Farida. Adsorptive removal of phenol by coffee residue activated carbon and commercial activated carbon: Equilibrium, kinetics, and thermodynamics. Journal of Chemical \& Engineering Data, v.55, n. 11, p. 4677-4686. 2010 doi:10.1021/je100302e

LAGO, R. C. A., ANTONIASSI, R.; FREITAS, S. C. Composição centesimal e de aminoácidos de café verde, torrado e de borra de café soluvel. In 2 Simposio de Pesquisa dos Cafés do Brasil. Anais. Vitoria, ES. p. 1473-1478. 2001. Disponível em:

<http://www.sapc.embrapa.br/arquivos/consorcio/spcb_anais/simposio2/industria09.p df>. Acesso em: 21 fev. 2019

LAGO, R. C. A.; ANTONIASSI, R. Composição de esteróis em óleos de café por cromatografia gasosa de alta resolução. In: SIMPÓSIO DE PESQUISA DOS CAFÉS DO BRASIL. Resumos expandidos. Poços de Caldas: Ministério da Agricultura e do Abastecimento, 2000. v. 2, p. 744-747.

MARIANO, F. A. F.; COUCEIRO, P. R. C.. Compósitos à Base de Carvão Ativado de Borra Oleosa e Óxidos de Ferro para Remoção de Contaminantes em Meio Aquoso, Revirtual Virtual Quimica, v. 7, n.6, p. 2202-2220. Data de publicação na Web: 22 de julho de 2015. ISSN 1984-6835. Diponível em:<http://www.uff.br/rvq>. Acesso em: 14 Mar 2019

MATOS, Antônio T...Tratamento e destinação final dos resíduos gerados no beneficiamento do fruto do cafeeiro. In: Zambolim, L. (ed.). Produção Integrada de Café. Viçosa: UFV/DFP; 2003. p.647-705.

MINISTÉRIO DA AGRICULTURA, PECUÁRIA E ABASTECIMENTO (MAPA). Café. Disponível em:< http://www.agricultura.gov.br/assuntos/politica-agricola/cafe>. Acesso em: 8 mar 2019. 
MOITINHO, Adriana Cerqueira; KRAUSE, Maurício Canielas ; SCHNEIDER, Jaderson Kleveston ; KRAUSE, Laiza Canielas ; CARAMÃO, Elina

Bastos.Caracterização do óleo extraído da borra de café industrial para aplicação como biodiesel In: III Congresso Nacional de Engenharia de Petróleo, Gás Natural e Biocombustíveis (CONEPETRO); V Workshop de Engenharia de Petróleo. Anais. v. 1, 2018, ISSN 2446-8339. Disponível em:

<http://www.editorarealize.com.br/revistas/conepetro/resumo.php?idtrabalho=214>. Acesso em: 5 Jun 2019

MOURA, Dante Henrique. Educação básica e educação profissional e tecnológica: dualidade histórica e perspectivas de integração. Holos, v. 2, p. 4-30, 2007.

Disponível em:

<http://www2.ifrn.edu.br/ojs/index.php/HOLOS/article/view/11> Acessado em: 8 jan 2019.

MOURA, C. L. de; MOREIRA, I. C.; DE LIMA, L. F.; SAKANAKA, L. S.. Extração e caracterização da composição Lipídica da borra de café robusta e arábica. In: XXV Congresso Brasileiro de Ciências e Tecnologia de Alimentos; X CIGR Section IV International Symposium. Anais. Gramado- RS. 24 a 27 de outubro de 2016. Disponível em:

<http://www.ufrgs.br/sbctars-eventos/xxvcbcta/anais/files/1339.pdf> Acesso em: 21 Mar. 2019

MOUSTAFA, Hesham; GUIZANI, Chamseddine; DUPONT, Capucine; MARTIN, Vincent; JEGUIRIM, Mejdi; DUFRESNE, Alain. Utilization of torrefied coffee grounds as reinforcing agent to produce high-quality biodegradable pbat composites for food packaging applications. ACS Sustainable Chemistry \& Engineering, v.5, n.2, p. 1906-1916. 2017. doi:10.1021/acssuschemeng.6b02633

ORECCHIO, Santino. Recovery and Reutilization of Waste Matter from Coffee Preparation: An Experiment for Environmental Science Courses. Journal of Chemical Education, v. 78 n.12, p. 166-1671. 2001 DOI: 10.1021/ed078p1669.

RAMOS, Rodrigo; ALVARENGA, Leonardo Henrique Cordeiro; DE PAULA, Silvia Maria; CARBONARI, Artur Wilson; DA SILVA, Marta. Produção de adsorventes a base de borra de café industrializado e folhas de corymbia citriodora (eucalipto limão). Revista Dissertar, v. 1, n. 28 e 29, p. 19-24, 2018. Disponível em:<http://revistadissertar.adesa.com.br/index.php/revistadissertar/article/view/2>. Acesso em: 21 fev. 2019

ROCHA, Cyntia Cristina da; REIS, César; CHAVES, Agnaldo Rodrigues de Melo. Caracterização qualitativa de ácidos graxos como componentes dos óleos de grão de café verde, café torrado e borra de café. In: VIII Simpósio de Pesquisa dos Cafés do Brasil. Anais. 25 a 28 de novembro de 2013, Salvador - BA. Disponível em: <http://www.sapc.embrapa.br/arquivos/consorcio/spcb_anais/simposio8/11.pdf> Acesso em: 21 fev. 2019

SANTOS, Jéssica Nascimento; HARAGUCHI, Dayana Missaki. Obtenção do biodiesel a partir de resíduos de café. In: XIX Congresso de Iniciação Científica da Universidade de Mogi das Cruzes (UMC). Anais. 2016. Disponível em: 
<http://www.umc.br/_img/_diversos/pesquisa/pibic_pvic/XIX_congresso/artigos/Jessi ca_Nascimento_Santos.pdf > Acesso em: 15 nov 2018.

SARRAF, M.H.S.; CORREAA, M.P.; SILVA, E.; DANTAS, K.G.F.; MARINHO, P.S.B. Eliminando odores: $O$ uso da borra de café como ferramenta no Ensino de adsorção para alunos da eeefm deodoro de mendonça. In: $56^{\circ}$ Congresso Brasileiro de Química (CBQ). Anais. 07 a 11 de novembro de 2016 Belem/ Para ISBN 978-8585905-19-4

SILVA, Luciano Luiz; CAPELEZZO, Ana Paula; CONTO, Stefane Vieira Besegatto Flavia; FERNANDES, Suellen Cadorin ; COSTELLI , Murilo Cesar; SAVIO, Juliana ; COLPANI, Gustavo Lopes. Utilização dos resíduos da extração do óleo bruto do café na produção de material adsorvente. Acta Ambiental Catarinense, v. 13, n. 1. 2016.

SILVA, Luis Carlos O.; FRANCA, Adriana S.; OLIVEIRA, Leandro S.. Utilização de borra de café na produção de adsorventes para remoção de compostos fenólicos. In: $8^{\circ}$ Encontro Brasileiro de Adsorção. Anais. 2010, Foz do Iguaçu-PR Brasil. Disponível em: <https://www.researchgate.net/publication/259000727_Utilizacao_de_borra_de_cafe _na_producao_de_adsorve ntes_para_remocao_de_compostos_fenolicos>. Acesso em: 15 Mar. 2019

SOMMUK, Krit; EAWLEX, Pichai; PRATEEPCHAIKUL, Gumpon. Optimization of coffee oil extraction from spent coffee grounds using four solvents and prototypescale extraction using circulation process. Agriculture and Natural Resources, v. 51, n. 3 , p.181-189. 2017. doi:10.1016/j.anres.2017.01.003

THIRÉ, Rossana; DIAS, Fernanda T. G.; ROSA, Roberta C. R. S.; ANDRADE, Cristina T.. Aproveitamento de resíduos da indústria cafeeira para a obtenção de compósitos termoplásticos à base de amido.In : $8^{\circ}$ Congresso Brasileiro de Polímeros ( $8^{\circ} \mathrm{CBPol}$ ), Vol. 1, p 262-264, Anais. Águas de Lindóia, SP, Brasil, 2005. Disponível em: <https://www.ipen.br/biblioteca/cd/cbpol/2005/PDF/298.pdf>. Acesso em: 18 abr 2019.

TOREZAN, Ranieri Mendes; SANTOS, Fernanda Cristina Storte. Reutilização da borra de café para produção de biocombustível. In: $17^{\circ}$ Congresso Nacional de Iniciação Científica. $17^{\circ}$ Conic-Semesp. Anais. 24 e 25 de novembro de 2017. Santo Amaro, São Paulo- SP. Disponível em: < http://conicsemesp.org.br/anais/files/2017/trabalho1000025979.pdf>. Acesso em: 14 Mar 2019.

VALENCIA, Nelson Rodriguez; FRANCO,Diego Antonio Zambrano. Los Subprodutos del café: fuente de energía renovable. In: Cenicafé, mar 2010. Avances Técnicos No. 393. ISSN: 0120-0178

VEGRO, Celso Luis Rodrigues; CARVALHO, Flavio Condé de. Disponibilidade e utilização de resíduos gerados no processamento agroindustrial do café. In: XXXI Congresso da Sociedade Brasileira de Economia e Sociologia Rural (SOBER). 
Anais. Bahia, 1993.Disponível em:<http://www.iea.sp.gov.br/ftpiea/ie/1994/tec10194.pdf> Acesso em: 3 Fev. 2019.

XAVIER, Lais Figueredo; LISBOA, Tatiane dos Santos; LULA, Ivana.

Reaproveitamento da Borra de Café na Obtenção de Biodiesel e de Carvão Ativado Para Tratamento de Rejeitos Industriais Têxteis. Scientia Amazonia, v. 6, n.2, 91108, 2017 Revista on-line. Disponível em: <http://scientia-amazonia.org/wpcontent/uploads/2017/01/v6-n2-91108-2017.pdf>. Acesso em: junho 2019 ISSN:223 